\title{
Çocuklarda pelvis ve asetabulum kırıkları
}

\author{
Pediatric pelvis and acetabulum fractures
}

\author{
Serkan Erkuş, Ali Turgut \\ Sağlık Bilimleri Üniversitesi, Tepecik Eğitim ve Araştırma Hastanesi, Ortopedi ve Travmatoloji Kliniği, İzmir
}

\begin{abstract}
Çocukluk çağında asetabulum ve pelvis kırıkları, tüm kırıklar arasında nadir görülür. Bu bölge kırıkları, genellikle yüksek enerjili yaralanmalar sonucu meydana gelmektedir. Özellikle, basit avulsiyon kırıkları gibi düşük enerjili spor yaralanmaları sonrası da pelvis kırığı gelişebileceği unutulmamalıdır. Çocuk pelvis kemiğinin elastisite ve periost yapısı ile remodelasyon özelliğinin, yaralanmalar sonrası gelişim döneminde yaşanabilecek büyüme problemlerine karşı koruyucu etkisi bulunmaktadır; ayrıca, bu özelliklerinden dolayı, yaralanması için yüksek enerji gerekir. Bu kırıklara, genellikle ek diğer sistem ya da çoklu kemik kırığı eşlik edebilir. Mortalite nedeni sıklıkla yetişkin hastalarda olduğu gibi kanama problemleri değil; eşlik eden diğer yaralanmalardır. Bu nedenle, pelvis kırığı olan hastaların çoğunluğu konservatif takip edilirken, asıl hasta yönetimi ek yaralanmalar zemininde oluşturulmalıdır.
\end{abstract}

Anahtar sözcükler: çocuk; pelvis kırıkları; asetabulum kırıkları; tedavi

\begin{abstract}
Acetabulum and pelvic fractures in childhood are rare among all fractures. Generally, these fractures occur as a result of high-energy injuries. It should be kept in mind that some pelvic fractures, especially simple avulsion fractures, may develop due to low energy sports injuries. The elasticity of the pediatric pelvic bone and the periosteum structure and remodeling feature have a protective effect against the growth problems that may occur during the post-injury period. Furthermore, due to these properties, high energy is necessary for any injury. These fractures may usually be accompanied by multiple organ injuries or bone fractures. The cause of mortality in children is often due to associated injuries, not hemorrhagic problems as seen in adults. For this reason, the majority of patients with pelvic fracture should be managed conservatively, and principle management should be based on the associated injuries.
\end{abstract}

Key words: pediatric; pelvic fractures; acetabulum fractures; treatment

\section{PELVIS KIRIKLARI}

Çocukluk çağı pelvis kırıkları nadir olarak görülse bile; doğası gereği yüksek enerjili yaralanma oluşu ve eşlik edebilen artmış diğer sistem yaralanmaları riski ile, travmatoloji alanında önemli ve dikkat gerektiren bir yer tutar. Güncel bilgiler ışığında, çocukluk çağı pelvis kırıkları görülme sıklığı \%0,8-1,6 iken; yaralanmanın mortalite oranları \%5-6,3 arasında değişmektedir. ${ }^{[1]}$ Çocuklar, yetişkinlerin ufaltılmış biçimleri değillerdir; dolayısıyla, çoğu zaman olduğu gibi, travmaya maruz kalmış çocuklar da, kemik kas iskelet sisteminin geçirdiği büyüme ve gelişme özelliğine göre kendi yaş grubu özelinde değerlendirilmelidir. Bilindiği üzere, çocuk pelvik kuşak kemikleri artmış plastisiteye, daha kalın ve daha güçlü "periosteum"a ve yaşla birlikte azalan remodelasyon özelliğine; sakroiliak eklem ve "simfizis pubis" ise artmış esnekliğe sahiptir. Bu özellikleri nedeniyle, pelvik bölge kırıklarının oluşması için yetişkin kemiğine göre daha yüksek enerji gerekir. Ancak unutulmamalıdır ki; düşük enerjili yaralanmalar sonrası avulsiyon kırıkları ya da stabil halka kırıkları gibi kırıkların görülmesi de mümkündür. ${ }^{[2]}$

Yaralanmanın etiyolojisi değerlendirildiğinde karşımıza çıkan en sık neden, yaya-araç kazalarından ileri gelen yüksek enerjili künt yaralanmalardır. Yüksekten düşme veya at biniciliği sırasında olan düşmeler; jimnastik, atletizm, futbol benzeri sporlarla uğraşan çocuk ve adolesanlarda avulsiyon kırıkları gibi sportif

- İletişim adresi: Doç. Dr. Ali Turgut, İzmir Tepecik Eğitim ve Araştırma Hastanesi, Güney Mah. Gaziler Cad. No: 468 Konak, İzmir Tel: 0537 - 0274425 e-posta: draliturgutort@yahoo.com.tr

- Geliș tarihi: 2 Șubat $2019 \quad$ Kabul tarihi: 2 Șubat 2019 
yaralanmalar; diğer nedenler arasında yer alır. Her ne kadar pelvis kırıkları, çocuk istismarında daha az yer tutsa da, tek başına görüldüğünde mutlaka bu yönde araştırılmalıdır. ${ }^{[1,2]}$

Pelvis kırı̆̆ı olan çocuk hastalarda kanamaya bağlı mortalite oranları düşük görülmesine rağmen; özellikle kafa içi, torakal veya abdominal yaralanmaların eşlik ettiği durumlarda klinik, hayatı tehdit edici yönde seyredebilmektedir. ${ }^{[3-6]}$ Chia ve ark.'nın 2004 yılında yaptıkları ve 120 hastayı içeren geriye dönük çalışmada; 21 pelvik ya da retroperitoneal kanaması olan sadece iki hastaya anjiyografi yapılmış ve bunlardan da sadece bir hastaya damar onarımı uygulanmıştır. Yetişkinlere göre kanamaya cevap vazokonstrüksiyonun daha etkili olduğunu düşünen Chia ve ark., çocukluk çağı pelvis kırıklarında hekimlerin asıl, eşlik eden yaralanmalar konusunda dikkatli olmaları gerektiğini ve mortalite oranlarının bu eşlik eden yaralanmalarla arttı̆̆ını bildirmişlerdir. Çalışmalarında, kafa travması olan \%44 $(n=53)$ hastanın üçünde, abdominal yaralanması olan \%17 $(n=20)$ hastanın da ikisinde ölüm olduğu bildirilmiştir.. ${ }^{[7]}$ Yazarlar, \%78 oranında eşlik eden yaralanma (\%44 kafa içi, \%40 uzun kemik kırığı, \%27 torasik yaralanma ve \%17 abdominal yaralanma) bildirmektedirler; bu güncel bilgiler ışığında, çocukluk çağı pelvis kırıklarında \%54-87 oranlarında, eşlik eden en az bir sistem yaralanması olduğu söylenebilir. ${ }^{[7,8]}$

Travmaya genel yaklaşım basamakları (A-B-C-D-E) sağlandıktan ve hastalar hemodinamik açıdan stabilleştirildikten sonra, her hasta ayrıntılı ve eksiksiz şekilde muayene edilmeli; tıbbi geçmişi irdelenmelidir. Fizik muayenede; ekimoz, kontüzyon, abrazyon, laserasyon gibi cilt lezyonları, deformiteler, anormal ekstremite duruşları tek tek incelenmeli ve eşlik edebilecek yaralanmalar açısından dikkatli olunmalıdır. Pelvis yaralanması olan çocuk hastalarda, klinik açıdan stabilizasyon sağlandıktan hemen sonra; travmaya ilk yaklaşım olarak, standart pelvis, servikal vertebra ve akciğer grafileri çekilmelidir. İkincil değerlendirmede ise, fizik muayenede şüphelenilen diğer bölgelerin de standart görüntüleme pozisyonlarında grafileri alınmalıdır. ${ }^{[2]}$ Pelvis kırı̆ıııın deplasman yönünü ve tiplendirmesini yapmak için inlet-outlet grafileri; asetabulum kırıkları için ise Judet oblik grafilerinin yol göstereceği bilinmelidir. Unutulmaması gereken bir konu da, direkt grafilerle pelvis kırıklarının ancak ortalama \%50'sinin ayırt edilebildiğidir. ${ }^{[9]} \mathrm{Bu}$ nedenle, pelvis kırığı veya diğer bölgelerde kemik bütünlüğü şüphesi var ise, bilgisayarlı tomografi (BT) yardımıyla ileri görüntüleme yapılmalıdır.

Pelvis kırıkları için literatürde pek çok sınıflama sistemi geliştirilmiştir. En sık kullanılan sınıflama sistemi Torode ve Zieg tarafından tanımlanmış olandır. Pelvik kırığı olan 141 hastanın değerlendirildiği çalışma sonrası, Torode ve Zieg, kırığın ciddiyeti ve prognozuna dair bir sınıflama sistemi geliştirmişlerdir (Tablo 1, Şekil 1). ${ }^{[6]}$ Bir başka sınıflama sistemi ise Tile ve ark. ${ }^{[10]}$ tarafından 2003 yılında kırığın oluş mekanizmasına göre daha önce Pennal ve ark.'nın ${ }^{[11]}$ tanımlamış olduğu sistemin modifikasyonudur. Silber ve Flynn ise, pelvis kırıklarını immatür ve matür (triradiat kıkırdağın kapandığı) grup olarak ikiye ayırmıştır. Bu sınıflamaya göre, immatür gruptaki tedavide genellikle konservatif takip ile eşlik eden yaralanmaların ön planda tutulması gerektiği; matür gruba ise yetişkin gruba benzer şekilde yaklaşılması gerektiği üzerine durulmuştur. ${ }^{[12]}$ Pelvis kırıklarında; anterior ve posterior halkada kırık, deplase pelvis, deplase posterior halka yaralanması, deplase triradiat kırık varlığı instabilite göstergeleridir. ${ }^{[2]}$

Çocukluk çağı pelvis yaralanmalarında uygun tedavi yönteminin seçimi; hastanın yaşı, eşlik eden diğer sistem yaralanmaları, kırığın tipi gibi değişkenlere göre planlanmalıdır. ${ }^{[13]}$ İmmatür pelvis kemiğinin, büyüme yönünde gelişmesi ve sahip olduğu yeniden şekillenme özelliği nedeniyle; bu kemiklerde çoğu kırık, istenmeyen bir durum gelişmeden iyileşebilir. ${ }^{[14]}$ Triradiat kıkırdağın açık olduğu durumlarda daha çok, Torode ve Zieg, Tip II ve III yaralanmalar görülürken; matürasyonla birlikte, asetabular ve posterior halkayı içeren, daha instabil ve komplikasyona açık kırıklar oluşabilmektedir. ${ }^{[15]}$ Güncel bilgilere bakıldığında pek çok yazar, geçmişte olduğu gibi, çocukluk çağında görülen ve özellikle immatür pelvis kırıkları için; yatak istirahati, iskelet traksiyonu veya pelvipedal alçılama gibi konservatif yöntemleri ön planda tutmaktadır. ${ }^{[8,13-16]}$ İnstabil kırıkları içeren güncel geriye dönük çalışmalara göre, uzun dönem morbidite sonuçları nedeniyle, özellikle de triradiat kıkırdak hasarı gibi durumlarda, gelişebilecek deformite ve büyüme bozukluklarına yönelik cerrahi tedaviye yönelimde artış söz konusudur. ${ }^{[2,8]}$ Güncel bilgilere göre farklı kırık tipleri için önerilen tedavi yöntemleri Tablo 2'de paylaşılmıştır.

Daha önce de belirtildiği üzere, çocuklarda mevcut olan, özellikle de immatür kemiklerde, remodelasyon özelliği, kalın periosteum varlığı, hızlı iyileşme özellikleri nedeniyle; pelvis kırıkları genellikle kötü kaynama ya da kaynamama dahil sekelsiz iyileşmektedir. Ancak, özellikle triradiat kıkırdağı içeren kırıklarda, büyüme alanının erken kapanması, bacak boyu eşitsizliği, pelvik asimetri, skolyoz, travmatik artritler, bel ağrısı, sakral kırıklara bağlı sinir kök yaralanmaları gibi bir takım istenmeyen durumlar da bildirilmiştir. ${ }^{[5,8,15,18]}$ 
Tablo 1. Torode ve Zieg pelvis kırığı sınıflandırma sistemi ${ }^{[6]}$

\begin{tabular}{|c|c|}
\hline Tip & Tanımlama \\
\hline $\mathbf{I}$ & Avulsiyon kırıkları \\
\hline \multirow[t]{3}{*}{ II } & İliak kanat kırıkları \\
\hline & a. Iliak apofiz ayrılması \\
\hline & b. İliak kemik kanadın kırı̆̆ı \\
\hline \multirow[t]{3}{*}{ III } & Basit halka kırıkları \\
\hline & a. Pubis kırıkları ve simfizis pubis ayrılmaları \\
\hline & b. Halka kırı̆̆ı olmaksızın asetabulum kırı̆̆ı \\
\hline \multirow[t]{4}{*}{ IV } & Ayrılmış halka kırıkları \\
\hline & a. İki taraflı inferior ve superior pubik kol kırı̆ı (Straddle [eyer] kırığı) \\
\hline & b. Pubik ramus veya simfizisi ve posterior halka \\
\hline & c. Pelvis anterior halka ve asetabulum arasında instabil segment oluşturan kırık \\
\hline
\end{tabular}

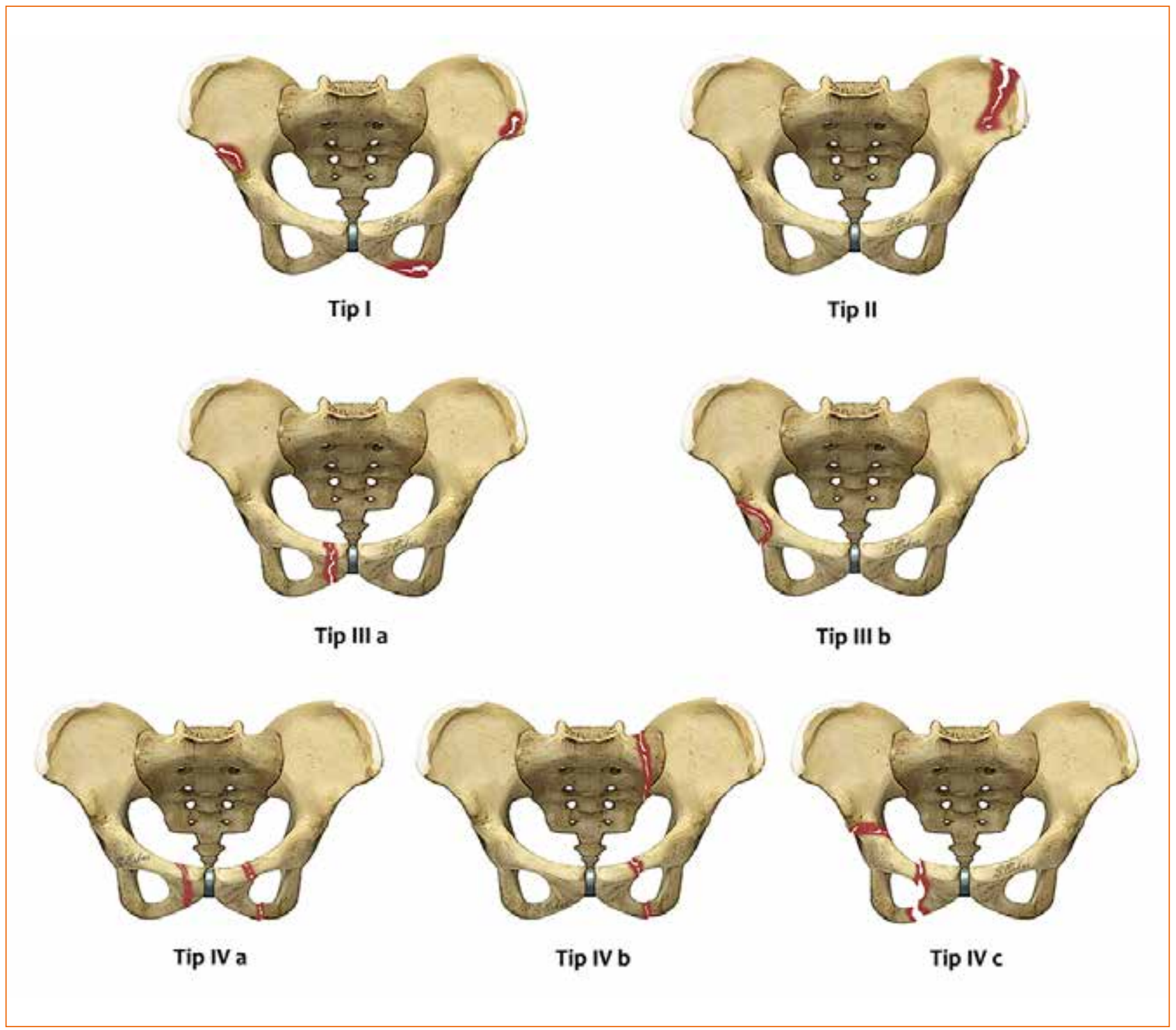

Şekil 1. Torode ve Zieg pelvis kırığı sınıflandırma sistemi. 
Tablo 2. Pelvis kırıklarında tedavi yöntemleri[ ${ }^{[2]}$

\begin{tabular}{|c|c|c|}
\hline $\begin{array}{l}\text { Kırık tipi } \\
\text { (Torode ve Zieg) }\end{array}$ & Kırık şekli & Önerilen tedaviler ve klinik seyir \\
\hline Tip I & Avulsiyon kırıkları & $\begin{array}{l}\text { Konservatif: İstirahat, iki veya daha fazla hafta için koltuk değneği ile kısmi yüklenme, kas } \\
\text { gerginliğini en aza indirgemek için ekstremite pozisyonlama. } \\
\text { Prognoz: Yaralanma öncesi aktivasyon derecesine geri dönüş. } \\
\text { Iskial ayrılma kırıkları } \\
\text { Akut tedavi tartışmalı; inatçı ağrı, oturma sırasında bası hissi, }>1-2 \mathrm{~cm} \text { deplasman eksizyonel } \\
\text { cerrahi işlemler için rölatif endikasyon. }\end{array}$ \\
\hline Tip II & iliak kanat kırıkları & $\begin{array}{l}\text { Konservatif: İstirahat, ağrı tolerasyonu için koltuk değneği ile kısmi yüklenme, semptomatik tedavi. } \\
\text { Prognoz: Genellikle sekelsiz iyileşme. }\end{array}$ \\
\hline Tip III & $\begin{array}{l}\text { Pubis ve iskiumun } \\
\text { basit kırıkları }\end{array}$ & $\begin{array}{l}\text { İpsilateral her iki ramus kırı̆̆ı } \\
\text { Konservatif: İstirahat, tedrici yük verme. } \\
\text { Prognoz: Remodelasyon ile iyileşme. } \\
\text { iskium kırıkları } \\
\text { Konservatif: İstirahat, tedrici yük verme. } \\
\text { Prognoz: Genellikle minimal deplasedir; tam iyileşme. } \\
\text { Simfiz pubis ayrışması } \\
>2,5 \text { cm ve >15० rotasyon deformitesi var ise instabilite açısından dikkatli olunmalı. } \\
\text { Konservatif: İstirahat, semptomatik tedavi. } \\
\text { Eksternal tespit: Belirgin ayrışma ya da posterior yaralanma eşlik ediyor ise stabilizasyon gerekir. } \\
\text { Sakroiliak eklem çıkık ve kırıkları } \\
\text { İzole olarak görülmesi nadirdir; genellikle anterior pelvis ayrılmaları ile birlikte görülmektedir. } \\
\text { Konservatif: İstirahat, koltuk değnekleri ile tedrici yüklenme. } \\
\text { Prognoz: Kronik bel ağrısı, nörolojik yaralanma var ise inkomplet iyileşme bildirilmiştir. }{ }^{[17]}\end{array}$ \\
\hline Tip IV & $\begin{array}{l}\text { Halka ayrılması } \\
\text { (instabil kırıklar) }\end{array}$ & $\begin{array}{l}\text { Straddle kırı̆̆ı } \\
\text { Üriner sistem yaralanmaları açısından dikkatli olunmalı. } \\
\text { Konservatif: İstirahat, semptomatik tedavi. } \\
\text { Kompleks kırıklar } \\
\text { Konservatif: Minimal deplase kırıklar için; semptomatik tedavi, yük verme kısıtlamaları, yakın } \\
\text { takip, küçük çocuklarda pelvipedal alçılama. } \\
\text { Cerrahi: Deplase matür kemik kırıkları, instabil immatür kemik kırıkları, eşlik eden diğer sistem } \\
\text { yaralanmalarında stabil pelvis ihtiyacı için; eksternal fiksatör, açık redüksiyon ve internal tespit. } \\
\text { Prognoz: Bacak boyu eşitsizliği, pelvis asimetrisi, bel ağrısı, skolyoz riski mevcut. }\end{array}$ \\
\hline
\end{tabular}

\section{ASETABULUM KIRIKLARI}

Asetabulum kırı̆̆ı, çocuk ve adolesanlarda çok nadir görülen pelvik yaralanmalar arasındadır. Bu nedenle, güncel bilgilerimiz ve çalışmalar, yetişkin asetabulum kırıklarına nazaran daha az seviyededir. ${ }^{[19-21]}$ Çocuklarda gelişen asetabulum kırı̆̆ının mekanizması yetişkinlere benzer ve femur başından aktarılan enerjinin asetabuluma yaptığı etki ile oluşur. ${ }^{[20]}$

Pelvis kemiğinin çocukluk çağı yapısal özellikleri ve immatürasyonun yeniden şekillenmeye izin vermesinin yanı sıra; komplikasyon gelişimi açısından, asetabular kırıklarda özellikle triradiat kıkırdağın yaralanması önemli bir yer tutmaktadır. Triradiat kıkırdağın yaralanmasına göre; özellikle 10 yaş öncesi, yaralanma sonrası gelişen kemik köprüler veya büyüme durması gibi durumlarda, asetabular displazi, asetabulum gelişiminde bozukluk ve bacak boyu eşitsizliği meydana gelebilir. ${ }^{[19]}$ Bucholz ve ark., 10 yaşından küçük çocuklarda asetabular büyüme ile ilgili komplikasyonların görülme riskinin arttığını bildirmişlerdir. ${ }^{[22]}$ Ayrıca yazarlar, asetabulum kırıkları için Salter-Harris (S-H) sınıflamasına dayanan bir gruplama yapmışlardır: Tip I: Makaslama kırı̆̆ (S-H Tip I ve Tip II kırı̆̆ı), Tip II: Ezilme kırı̆̆ı (S-H Tip V, kötü 


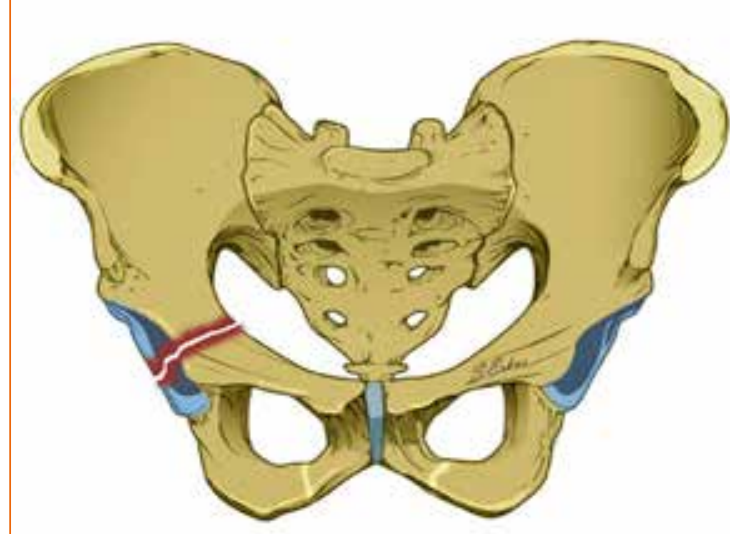

S-H Tip I kırık

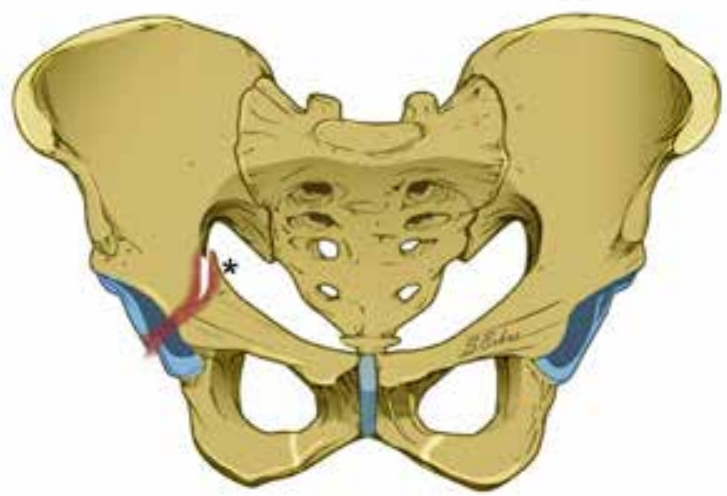

S-H Tip II kırık (*Thurston-Holland parçası)

\section{Bucholz Tip I kırık: Makaslama}

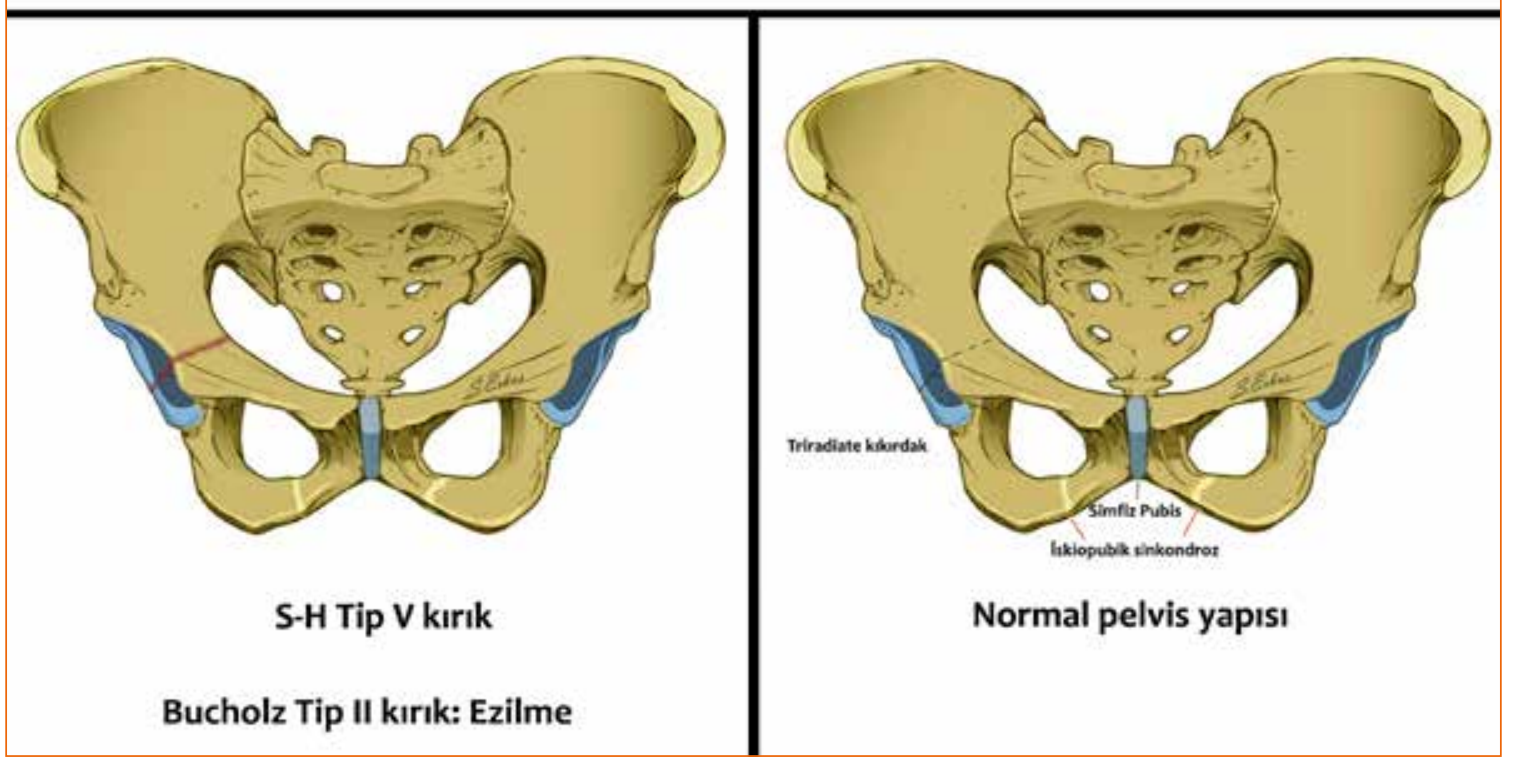

Şekil 2. Bucholz asetabulum kırı̆ı sınıflandırma sistemi (S-H, Salter-Harris).

prognoz) (Şekil 2). Benzer şekilde Trousdale ve Ganz, triradiate kıkırdak yaralanması sonrası kalça displazisi gelişen ve ortalama yaşın üç olduğu beş hastalık bir seri yayımlamışlardır. Yazarlar travma sonrası displazi gelişiminde en önemli değişkenlerin yaş ve travma ciddiyeti olduğu üzerine durmuşlardır. ${ }^{[23]}$

Asetabulum kırığı olan hastalarda tanı genellikle standart grafiler ile konulmaktadır; ancak eklem aralığında uyumsuzluk veya farklılık varsa, eklem faresi gibi serbest cisim ya da osteokondral lezyon varlığı şüphemiz varsa özellikle de immatür pelvisi olan çocuklarda ileri inceleme yöntemleri düşünülebilir.
Asetabulum kırığına eşlik eden kalça eklem çıkı̆̆ı var ise, bilgisayarlı tomografi (BT) yanı sıra manyetik rezonans incelemesi kapsüler defektleri, konsantrik eklem redüksiyonunu engelleyebilecek yumuşak doku transpozisyonlarını, osteokondral lezyonu ayırt etmede yol gösterici olabilmektedir. ${ }^{[20]}$

Asetabulum kırıklarında tedavinin amacı iki temele dayanmaktadır: 1) Anatomik redüksiyonu sağlanmış eklem yüzü ile uyumlu ve stabil bir kalça eklemi elde etmek; 2) Normal büyümenin devamı için triradiate kıkırdağın dizilimini korumak. ${ }^{[2]}$ Bu kırıklarda matür pelvis için yetişkinlere benzer yaklaşım yapılırken, immatür 
pelviste triradiate kıkırdağın yaralanması tedaviyi belirlemede etkilidir. Çoğu immatür pelviste asetabulum kırığı zamanla herhangi bir sekel gelişmeden iyileşebildiği için ön planda yatak istirahati ve hasta uyumunun sağlandığı yaşlarda tedrici yüklenmeleri içeren konservatif yöntemler uygulanmaktadır. Bunun yanı sıra, deplasman miktarı 2 mm'den fazla olup cerrahi için genel durumu uygun olmayan hastalarda, minimal deplasmanı olan hastalarda distal femurdan iskelet traksiyonu da yapılabilir. Eğer kırıkta yer değiştirme 2 mm'den daha fazla, kırık instabil, eklem devamsızlığı veya eklem içi serbest parça var ise açık redüksiyon ile internal tespit uygulanır. ${ }^{[2,19-21]}$

\section{Deneyimimiz}

2000-2010 yılları arasında kliniğimizce takip edilmiş 26 hastanın geriye dönük olarak yapılan incelemesinde güncel literatür bilgilerine benzer sonuçlar elde edilmiştir. ${ }^{[24]}$ On altı erkek, 10 kızın dâhil olduğu çalışmada, ortalama yaş 10,5 (2-16), ortalama yatış süresi 3,5 (1-17) gün idi. On dört hastada araç dışı, iki hastada araç içi olmak üzere toplam 16 hastada trafik kazası; 10 hastada ise yüksekten düşme sonrası pelvis yaralanması mevcuttu. Torode ve Zeig sınıflamasına göre ise bir hastada Tip II, 22 hastada Tip III ve üç hastada Tip IV yaralanma vardı. On hastada ek yaralanma yok iken 16 hastada ek yaralanma ( 6 diğer kemik kırığı, 4 kafa travması, 2 genitoüretral yaralanma) mevcuttu. Sadece üç hastada retroperitoneal kanama mevcuttu. Bütün hastaların pelvis kırı̆ı konservatif olarak takip edilmiş; uygun rehabilitasyon programı ile mobilizasyonları sağlanmıştır. Sadece bir hasta, tibia kırığı nedeniyle titanyum elastik çivileme yöntemi ile ameliyat edilmiştir. İnstabil olan üç hasta da dâhil tüm hastaların klinik takiplerinde herhangi bir şikayet gelişmemiştir (Şekil 3-6).
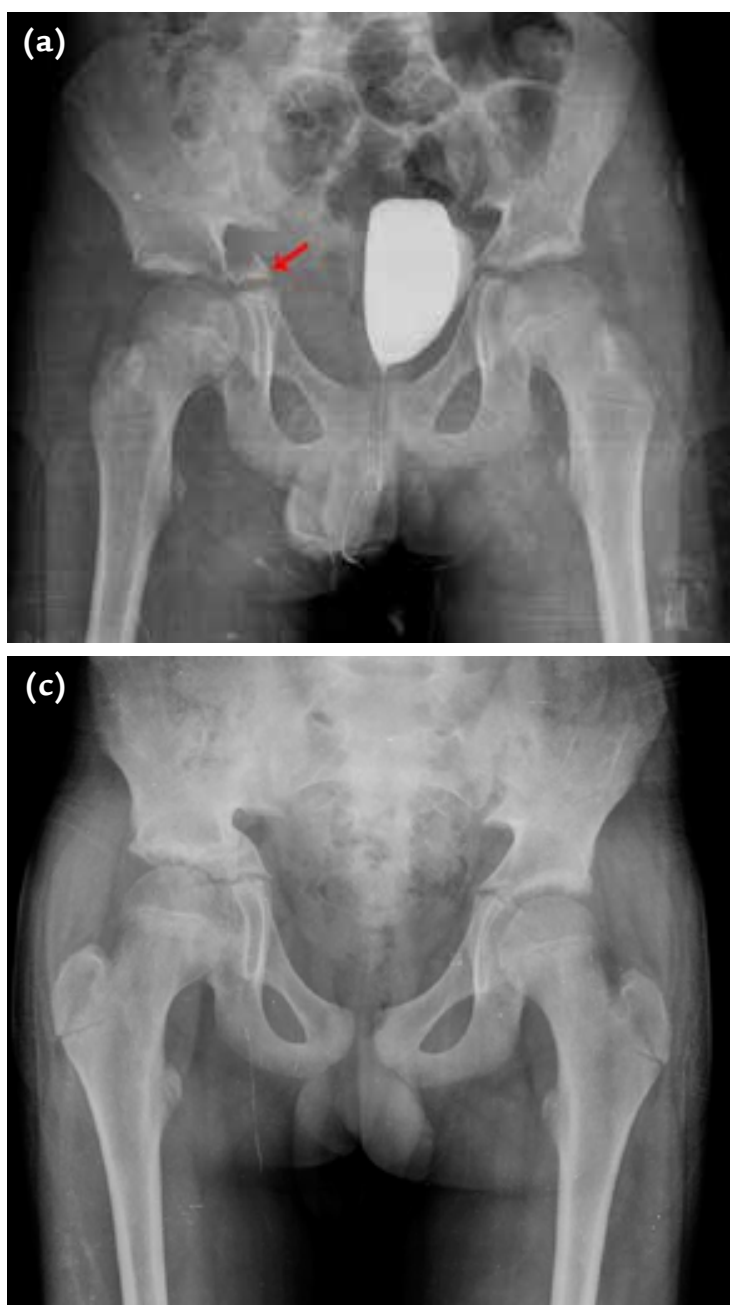

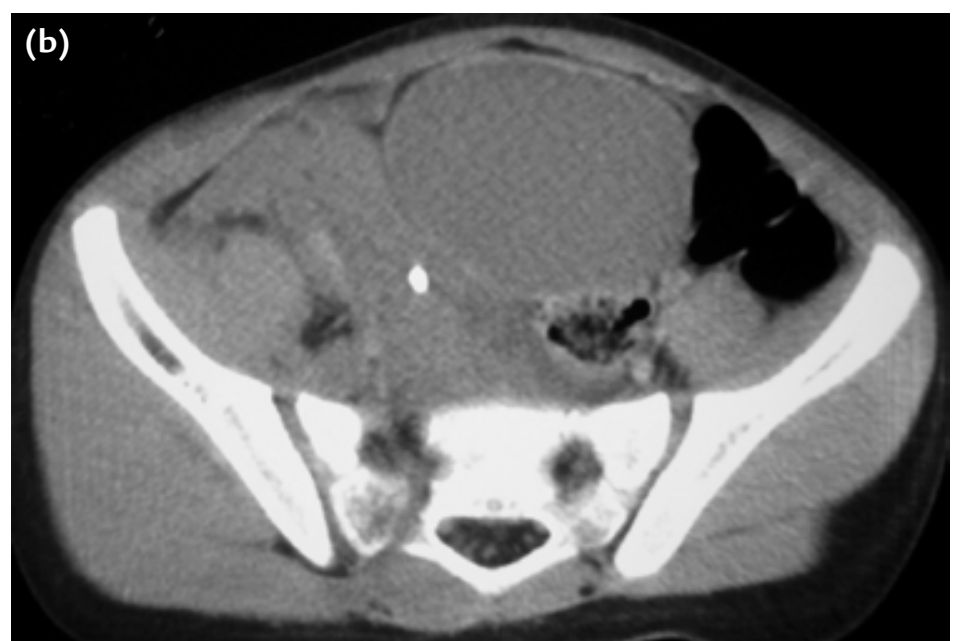

Şekil 3. a-c. On üç yaşındaki erkek hasta, araç dışı trafik kazası sonrası tarafımızca konservatif olarak takip edildi. Asetabuluma ait Bucholz sınıflaması Tip I kırığı mevcuttu. Kırığa ait metafız (ThurstonHolland) parçası görülmekte (kırmızı ok). Eşlik edebilecek üriner sistem yaralanması için hastaya ileri görüntüleme yapılmıştı (a). Hastanın BT kesitlerinde sakruma ait kırık hattı olduğu da görülmektedir (b). Hastanın, konservatif takip sonrası yaralanmanın ikinci yılına ait direkt grafileri görülmektedir (c). Hastanın takiplerinde herhangi bir problem saptanmamış ve remodelasyon ile iyileşme görülmüştür. 

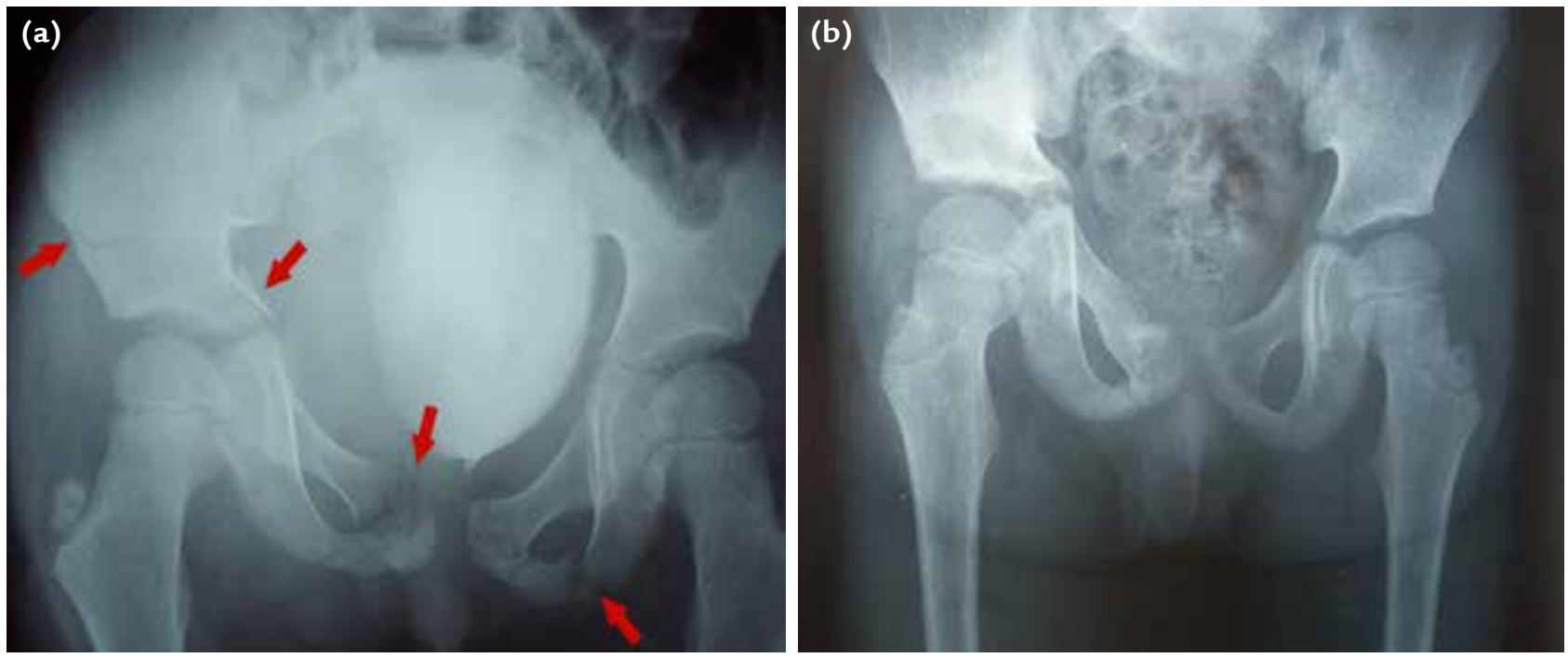

Şekil 4. a, b. Yedi yaşındaki erkek hastanın, araç dışı trafik kazası sonrası gelişen çoklu pelvis kırığı. Bilateral pubik ramus, să̆ asetabulum ve sağ ilium ayrışmamış kırık hatları gösterilmiştir (kırmızı oklar). Torode ve Zieg sınıflaması Tip IVc kırı̆̆ı olarak kabul edilmiş (a), konservatif olarak tedavi edilmiştir. Yaralanmadan sonraki birinci yılına ait kontrol grafisinde, kaynamanın tam olarak sağlandığı ve herhangi bir gelişim problemi olmadığı görüldü (b).

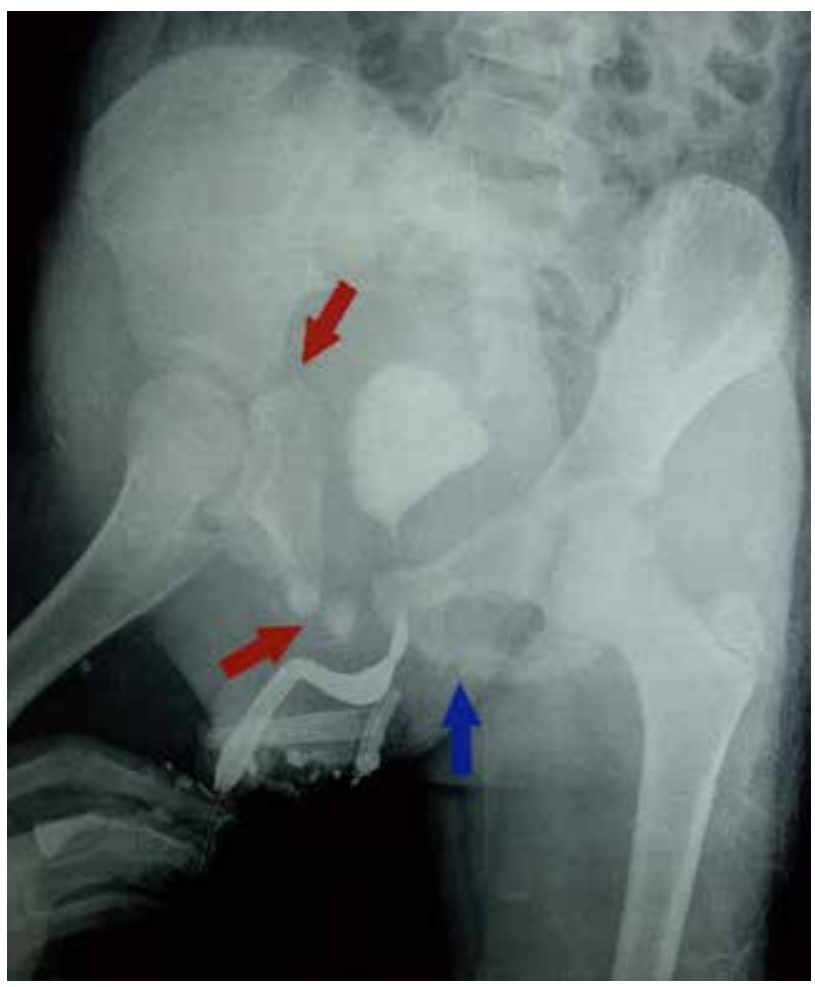

Şekil 5. Yedi yaşındaki erkek hastanın, araç içi trafik kazası sonrası gelişen ve asetabulumu içeren Torode ve Zieg Tip IVc kırığı. Sağ asetabulum S-H Tip I ve sağ pubik ramus kırık hatları gösterilmiştir (kırmızı oklar). İskiopubik sinkondroz görülmekte (lacivert ok).

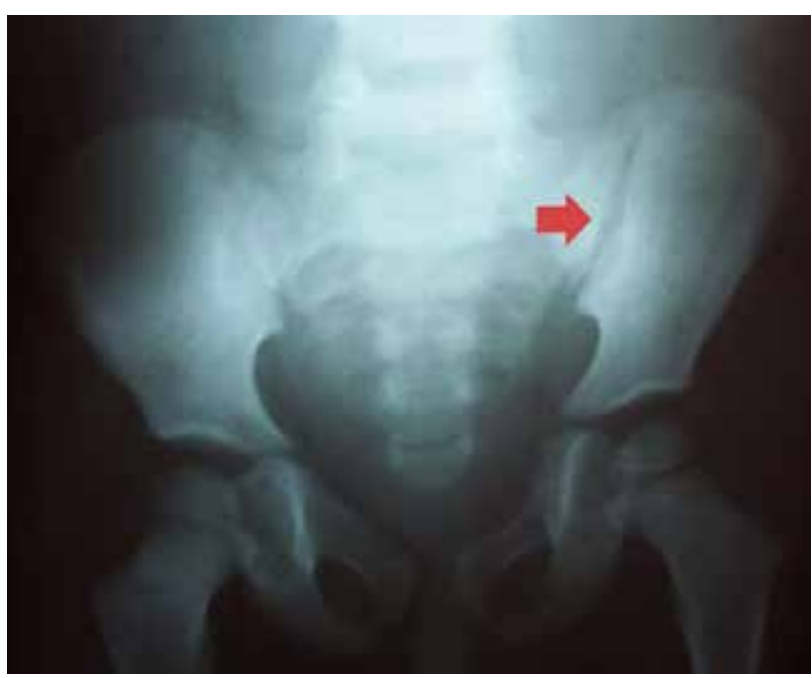

Şekil 6. Beş yaşındaki erkek hastanın, yüksekten düşme sonrası ilium kırı̆̆ı (Torode ve Zieg Tip II) tarafımızca konservatif olarak takip edildi. Takiplerinde herhangi bir hemorajik problem gelişmedi. 


\section{Sonuç}

Çocukluk çağında görülen pelvis kırıkları, basit avulsiyon kırıklarından instabil kırıklara uzanan geniş bir yelpazede karşımıza çıkmaktadır. Yaralanmanın yüksek enerjili olması nedeniyle mutlaka, bu travmaya maruz kalmış çocuk ve adolesanlar klinik açıdan stabil olmaları sağlandıktan hemen sonra ayrıntılı şekilde değerlendirilmeli; eşlik eden yaralanmalar açısından uygun tedavileri başlatılmalıdır. Unutulmamalıdır ki; bu hastaların kemik yapıları ve anatomik özellikleri yetişkinlerden farklı olduğu için, bu yaralanmalarda hemorajik komplikasyonların görülme ihtimali daha nadirdir. Hastaya yaklaşımda tedavi seçeneklerinde ön planda konservatif yöntemler bulunmaktadır. Her ne kadar, kemik yapının remodelasyon özelliği iyi olsa da hastalarda özellikle triradiat kıkırdak hasarı var ise normal büyüme ve gelişme açısından yakın takip edilmelidir.

\section{KAYNAKLAR}

1. Rickert KD, Hosseinzadeh P, Edmonds EW. What's New in Pediatric Orthopaedic Trauma: The Lower Extremity. J Pediatr Orthop 2018;38(8):e434-9. Crossref

2. McCarthy J, Herman MJ, Sankar WN. Pelvic and Acetabular Fractures. İçinde: Flynn JM, Skaggs DL, Waters PM. Rockwood and Wilkins' Fractures in Children, 8th ed. Philadelphia: Wolters Kluwer Health; 2015. ss.921-52.

3. Grisoni N, Connor S, Marsh E, Thompson GH, Cooperman DR, Blakemore LC. Pelvic fractures in a pediatric level I trauma center. J Orthop Trauma 2002;16(7):458-63. Crossref

4. Silber JS, Flynn JM, Koffler KM, Dormans JP, Drummond DS. Analysis of the cause, classification, and associated injuries of 166 consecutive pediatric pelvic fractures. J Pediatr Orthop 2001;21(4):446-50. Crossref

5. Rieger $\mathrm{H}$, Brug E. Fractures of the pelvis in children. Clin Orthop Relat Res 1997;336:226-39. Crossref

6. Torode I, Zieg D. Pelvic fractures in children. J Pediatr Orthop 1985;5(1):76-84. Crossref

7. Chia JPY, Holland AJA, Little D, Cass DT. Pelvic fractures and associated injuries in children. J Trauma 2004;56(1):83-8. Crossref

8. Subaşı M, Cebesoy O, Işık M, Gerçekcioğlu A. Çocukluk çağı pelvis kırıkları. TOTBID Derg 2008;7(3-4);116-20.

9. Guillamondegui OD, Mahboubi S, Stafford PW, Nance ML. The utility of the pelvic radiograph in the assessment of pediatric pelvic fractures. J Trauma 2003;55(2):239-40. Crossref
10. Tile M. Helfet DL, Kellam JF. eds. Fractures of the Pelvis and Acetabulum, 3rd ed. Baltimore: Lippincott Williams \& Wilkins; 2003.

11. Pennal GF, Tile M, Waddel JP, Garside H. Pelvic distruption: assessment and classification. Clin Orthop Relat Res 1980;(151):12-21. Crossref

12. Silber JS, Flynn JM. Changing patterns of pediatric pelvic fractures with skeletal maturation: implications for classification and management. J Pediatr Orthop 2002;22(1):22-6. Crossref

13. Holden $\mathrm{CP}$, Holman J, Herman MJ. Pediatric pelvic fractures. J Am Acad Orthop Surg 2007;15(3):172-7. Crossref

14. Blasier RD, McAtee J, White R, Mitchell DT. Disruption of the pelvic ring in pediatric patients. Clin Orthop Relat Res 2000;376:87-95. Crossref

15. Sağlam Y, Dikmen G, Bademler S, Aksoy M, Dikici F. Analysis of the cause, classification, treatment, outcome and associated injuries of pediatric pelvic ring fractures. Ulus Travma Acil Cerrahi Derg 2015;21(5):392-6. Crossref

16. Quick TJ, Eastwood DM. Pediatric fractures and dislocations of the hip and pelvis. Clin Orthop Relat Res 2005;(432):8796. Crossref

17. Heeg $M$, Klasen $H J$. Long-term outcome of sacroiliac distruptions in children. J Pediatr Orthop 1997;17(3):33741. Crossref

18. Schwarz N, Posch E, Mayr J, Fischmeister FM, Schwarz AF, Öhner T. Long term results of unstable pelvic ring fractures in children. Injury 1998;29(6):431-3. Crossref

19. Başaran SH, Bilgili MG, Kural C, Bayrak A, Avkan MC. Çocuklarda asetabulum kırığı: ender bir olgu sunumu. Cumhuriyet Tip Derg 2013;35(1):109-12. Crossref

20. Kruppa CG, Sietsema DL, Khoriaty JD, Dudda M, Schildhauer TA, Jones CB. Acetabular Fractures in Children and Adolescents: Comparison of Isolated Acetabular Fractures and Acetabular Fractures Associated With Pelvic Ring Injuries. J Orthop Trauma 2018;32(2):e39-45. Crossref

21. DeFrancesco CJ, Sankar WN. Traumatic pelvic fractures in children and adolescents. Semin Pediatr Surg 2017;26(1):2735. Crossref

22. Bucholz RW, Ezaki M, Ogden JA. Injury to the acetabular triradiate physeal cartilage. J Bone Joint Surg Am 1982;64(4):600-9. Crossref

23. Trousdale RT, Ganz R. Posttraumatic acetabular dysplasia. Clin Orthop Relat Res 1994;305:124-32. Crossref

24. Turgut A, Kalenderer O, Gunaydin B, Korkmaz M, llyas G, Ipci FB. Demographic characteristics of paediatric pelvic fractures: 10-years' experience of single paediatric orthoaedics clinic. Eurasian J Med 2015;47(2):130-4. Crossref 